\title{
Morphologic Abnormalities in Human Infant Cerebral White Matter Related to Gestational and Postnatal Age
}

\author{
ALAN LEVITON AND FLOYD H. GILLES $(21)$ \\ Departments of Neurology and Pathology (Neuropathology), The Children's Hospital Medical Center \\ and the Department of Neurology, Harvard Medical School, Boston, Massachusetts, USA
}

\section{Extract}

The risk of selected groupings of morphologic abnormalities of infant cerebral white matter as a function of total (i.e., gestational plus postnatal) age was studied in infants who had bacteria in cardiac blood aspirated at autopsy. The peak risk of hypertrophic astrocytes (HA) occurred at a younger age than the peak risk of $\mathrm{HA}$ and perivascular amphophilic globules (GL), which in turn occurred at a younger age than the combination of $\mathrm{HA}, \mathrm{GL}$, and necrotic foci (NF). These findings are considered compatible with the hypothesis that in infants with bacteremia, morphologic abnormalities in cerebral white matter are a function of total age.

\section{Speculation}

In infants (with or without bacteremia) morphologic abnormalities in cerebral white matter are a function of total age.

Perinatal telencephalic leucoencephalopathy (PTL) has been defined as the occurrence of both $\mathrm{HA}$ and GL in the cerebral white matter of infants free of diseases acknowledged as neurotoxic (13). The definition is based, in part, on the observation that HA have been shown to occur significantly more frequently with GL than would be expected if the occurrence of $\mathrm{HA}$ and $\mathrm{GL}$ were independent.

We have tried to determine whether the entity characterized by $\mathrm{HA}$ without GL in infant cerebral white matter $(\mathrm{HA} \cdot \overline{\mathrm{GL}})$ (18) and/or the entity of GL without $\mathrm{HA}(\overline{\mathrm{HA}} \cdot \mathrm{GL})$ are early or "incomplete" manifestations of PTL (HA.GL) (14). Of the limited number of risk factors evaluated to date, postmortem bacteremia (PMB) is the only one clearly associated with $\mathrm{HA} \cdot \mathrm{GL}$ (15). The ways in which PMB may be related to PTL are presently under study. In neonatal kittens, intraperitoneal administration of an endotoxin is followéd by the development of gliotic and necrotic lesions in telencephalic white matter not seen in unexposed littermates (7). No abnormalities, however, were seen in the brains of adult cats exposed to endotoxin. Thus, the relation of PMB to PTL may reflect the adverse effects of endotoxin on some maturational process unique to developing brain, such as myelinogenesis.

The results of an attempt to determine whether or not $\mathrm{HA} \cdot \overline{\mathrm{GL}}$ and $\overline{\mathrm{HA}} \cdot \mathrm{GL}$ were also associated with $\mathrm{PMB}$ led us to consider the hypothesis that in infants with bacteremia, morphologic abnormalities in cerebral white matter are a function of gestational plus postnatal age.

\section{MATERIALS AND METHODS}

The sample studied consisted of all 191 infants who survived birth, died before the 4th postnatal month with systemic diseases not known to injure neonatal central nervous system, were free of gross intracranial abnormalities that could possibly injure white matter, had postmortem examinations at The Children's Hospital Medical Center of Boston between January 1, 1965 and December 31, 1967, and for whom adequate data were available.

The procedure for preparation of material for neuropathologic study is detailed elsewhere (8). The slides of all 191 infants were examined during a 6-month period in 1968 separately by each of two neuropathologists. For the first part of the study, each infant was placed into one of four mutually exclusive and exhaustive morphologic subsets: (1) presence of the combination of HA and GL (PTL), (2) presence of HA but absence of $\mathrm{GL}(\mathrm{HA} \cdot \overline{\mathrm{GL}}),(3)$ Presence of GL but absence of $\mathrm{HA}(\overline{\mathrm{HA}} \cdot \mathrm{GL})$, and (4) absence of HA and GL. For the second part of this study, infants with $\mathrm{HA}$ and $\mathrm{GL}$ were subdivided into those with foci of necrosis (HA.GL-NF) and those without NF $(\mathrm{HA} \cdot \mathrm{GL} \cdot \overline{\mathrm{NF}})$.

Autopsy records were reviewed without knowledge of white matter histology and information about selected characteristics was obtained. These characteristics were: (1) gestational age, (2) postnatal age at death, and (3) whether or not an organism was cultured from blood aspirated from the heart at the time of postmortem examination. An infant was considered preterm when the duration of gestation was less than 36 weeks by history (43 infants). When the duration of gestation was not known, the criteria for classifying an infant as preterm were crown-heel length of less than $45 \mathrm{~cm} \mathrm{(11),} \mathrm{and}$ histologic evidence of glomerulogenesis (8) (8 infants). Crown-heel length was used to estimate duration of gestation for calculation of total age (see below) (11).

For most evaluation procedures the sample was divided simply into younger and older halves (postnatal age at death less than 9 days, postnatal age at death equal to or greater than 9 days). "Total age" is the name we give to the sum of gestational and postnatal ages. Total age was divided into four groups: 36 weeks or less (12 infants), 37-39 weeks (9 infantś), 40-42 weeks (17 infants), and greater than 42 weeks (15 infants).

Two null hypotheses were evaluated. First, PMB is not associated with $\mathrm{HA} \cdot \overline{\mathrm{GL}}, \overline{\mathrm{HA}} \cdot \mathrm{GL}$, or $\mathrm{HA} \cdot \mathrm{GL}$ in any of the four subsets of the sample classified by whether infants were born preterm or at term, and whether or not they died before the 9th postnatal day. Chi squares were calculated with Yates' 
correction for continuity. Fisher's exact test was used according to the recommendations of Cochran (2). Second, in the sample with $\mathrm{PMB}$, the distributions of infants with $\mathrm{HA} \cdot \overline{\mathrm{GL}}, \mathrm{HA} \cdot \mathrm{GL} \cdot \overline{\mathrm{NF}}$, and $\mathrm{HA} \cdot \mathrm{GL} \cdot \mathrm{NF}$ by total age do not differ from one another. The second hypothesis was evaluated graphically and by calculation of chi square.

\section{RESULTS}

Preterm infants who died before the 9th postnatal day comprise the only one of four groups in which the association of $\mathrm{HA} \cdot \overline{\mathrm{GL}}$ with $\mathrm{PMB}$ achieves nominal statistical significance (Table 1).

$\overline{\mathrm{HA}} \cdot \mathrm{GL}$ is not associated with $\mathrm{PMB}$ in any of the four subsets of the population defined by gestational and postnatal age (Table 2).

In term infants who died before the 9 th postnatal day, the association of $\mathrm{HA} \cdot \mathrm{GL}$ with $\mathrm{PMB}$ is highly significant $(P<$ 0.001 ) (Table 3 ). In preterm and term infants who died on or after the 9 th postnatal day, the association of $\mathrm{HA} \cdot \mathrm{GL}$ with PMB does not achieve nominal statistical significance. There appears to be no association of $\mathrm{HA} \cdot \mathrm{GL}$ with PMB in preterm infants who died before the 9 th postnatal day.

In the population of infants with PMB, the peak risk of $\mathrm{HA} \cdot \overline{\mathrm{GL}}$ occurs at a younger total age than the peak risk of $\mathrm{HA} \cdot \mathrm{GL} \cdot \overline{\mathrm{NF}}$, which in turn occurs at a younger total age than $\mathrm{HA} \cdot \mathrm{GL} \cdot \mathrm{NF}$, (Fig. 1). The distribution of infants with $\mathrm{HA} \cdot \overline{\mathrm{GL}}$ $\mathrm{HA} \cdot \mathrm{GL} \cdot \overline{\mathrm{NF}}$, and $\mathrm{HA} \cdot \mathrm{GL} \cdot \mathrm{NF}$ within the four subsets of the population classified by total age is highly unlikely to occur by chance $\left(\chi^{2}=20.8\right.$, with 6 d.f. $\left.P<0.01\right)$.

$\mathrm{HA} \cdot \overline{\mathrm{GL}}$ and $\mathrm{HA} \cdot \mathrm{GL}$ appear to be associated with $\mathrm{PMB}$ in separate subsets of the population classified by gestational and postnatal age. $\mathrm{HA} \cdot \overline{\mathrm{GL}}$ appears to be associated with $\mathrm{PMB}$ in the "youngest" subset (in terms of approximate total age), whereas $\mathrm{HA} \cdot \mathrm{GL}$ is apparently associated with $\mathrm{PMB}$ in an "older" subset. In none of these four subsets, however, does PMB seem to be associated with both $\mathrm{HA} \cdot \overline{\mathrm{GL}}$ and $\mathrm{HA} \cdot \mathrm{GL}$. These observations are compatible with the hypothesis that $\mathrm{HA} \cdot \overline{\mathrm{GL}}$ is an early or incomplete manifestation of PTL. On the other hand, they provide no support for the hypothesis that $\overline{\mathrm{HA}} \cdot \mathrm{GL}$ is an early or incomplete manifestation of PTL.

\section{DISCUSSION}

The data reported here are in keeping with the broad hypothesis that whether or not an infant with bacteremia has $\mathrm{HA} \cdot \mathrm{GL}$ or $\mathrm{HA} \cdot \mathrm{GL}$ is in some way related to gestational and/or

Table 1. Fourfold tables of relation of postmortem bacteremia $(P M B)$ to hypertropic astrocytes without amphophilic globules $(H A \cdot \overline{G L})$ in four mutually exclusive and exhaustive subgroups of population classified by gestational and postnatal age dichotomies ${ }^{1}$

\begin{tabular}{|c|c|c|c|c|c|c|c|c|}
\hline & \multicolumn{4}{|c|}{ Preterm } & \multicolumn{4}{|c|}{ Term } \\
\hline & \multicolumn{2}{|c|}{$\begin{array}{c}\text { PMB } \\
\left(<9 \text { days }^{2}\right)\end{array}$} & \multicolumn{2}{|c|}{$\begin{array}{c}\text { PMB } \\
(\geq 9 \text { days })\end{array}$} & \multicolumn{2}{|c|}{$\begin{array}{c}\text { PMB } \\
(<9 \text { days })\end{array}$} & \multicolumn{2}{|c|}{$\begin{array}{c}\text { PMB } \\
(\geq 9 \text { days })\end{array}$} \\
\hline & + & - & + & - & + & - & + & - \\
\hline \multicolumn{9}{|c|}{$\mathrm{HA} \cdot \overline{\mathrm{GL}}$} \\
\hline+ & 4 & 2 & 2 & 3 & 2 & 13 & 0 & 7 \\
\hline- & 5 & 24 & 5 & $\overline{6}$ & $\overline{17}$ & $\overline{29}$ & 18 & 55 \\
\hline & \multicolumn{2}{|c|}{$\begin{array}{lll}2 & 2 & 0\end{array}$} & \multicolumn{2}{|c|}{$p=0.63$} & \multicolumn{2}{|c|}{$\begin{array}{c}x^{2}=1.99 \\
0.1<P<02\end{array}$} & \multicolumn{2}{|c|}{$x^{2}=1.05$} \\
\hline
\end{tabular}

\footnotetext{
${ }^{1}$ Only in preterm infants who died before the 9 th postnatal day does the association of $\mathrm{HA} \cdot \overline{\mathrm{GL}}$ with $\mathrm{PMB}$ achieve nominal statistical significance.

${ }^{2}$ Postnatal age.
}

Table 2. Fourfold tables of the relation of postmortem bacteremia $(P M B)$ to morphologic entity characterized by $\overline{H A} \cdot G L^{1}$

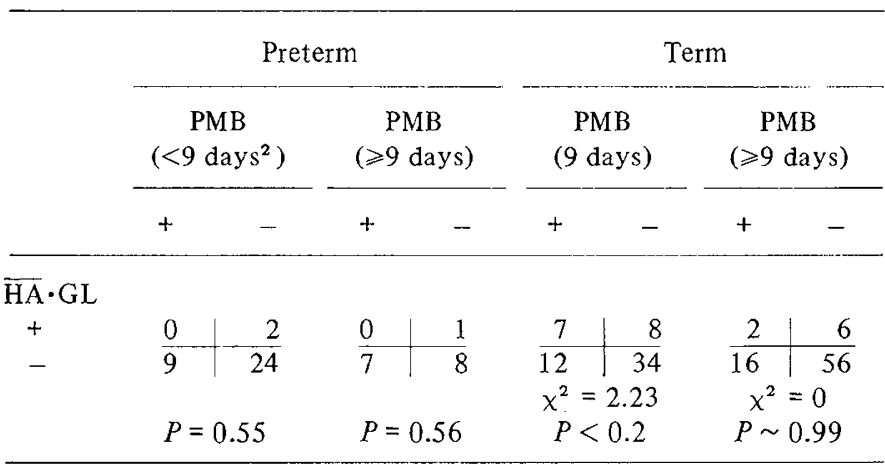

${ }^{1}$ The association of $\overline{\mathrm{HA}} \cdot \mathrm{GL}$ with $\mathrm{PMB}$ does not achieve nominal statistical significance in any of the four subsets of the population.

${ }^{2}$ Postnatal age.

Table 3. Fourfold tables of relation of postmortem bacteremia $(P M B)$ to hypertropic astrocytes with amphophilic globules $(H A \cdot G L)^{1}$

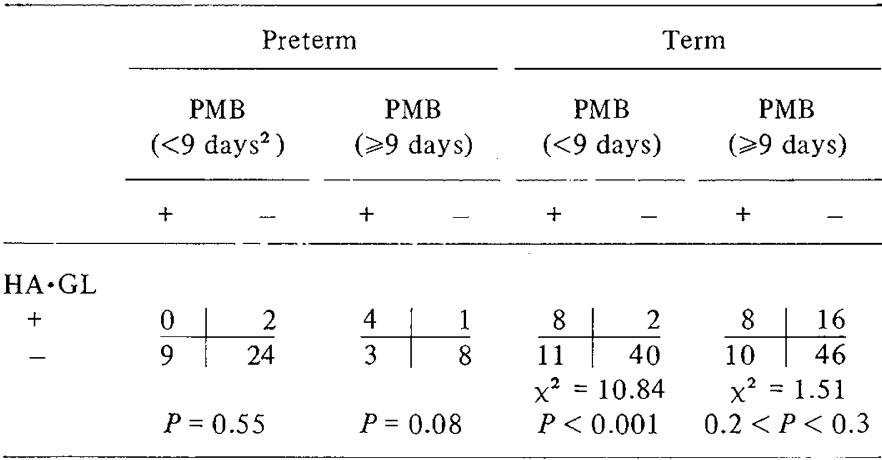

${ }^{1} \mathrm{HA} \cdot \mathrm{GL}$ appears to be associated with PMB in all groups except preterm infants who died before the 9 th postnatal day.

${ }^{2}$ Postnatal age.

postnatal age. In what way, however, are these morphologic abnormalities a function of age? One explanation is that in certain age subsets PMB tends to occur alone, whereas in other subsets PMB tends to occur with an as yet unidentified risk factor that is associated with GL. Another explanation is that the different morphologic patterns following a single, qualitatively unique insult reflect $(l)$ quantitative differences in the insult, and/or (2) age-dependent differences in the ability of the infant brain to respond to the insult. The latter possibility was evaluated to a greater detail because it appeared to be the most reliably and easily studied of the possibilities.

Although it is not known in our series of patients at which time in an infant's life the white matter was damaged, a limited evaluation is possible if one assumption is made. This assumption is that the insult did not occur any earlier than the last few days of gestation. This is in keeping with reports that in infants who survive birth, neonatal bacteremia tends to be acquired no earlier than the immediate perinatal period $(1,3$, $10)$.

Preterm infants have a lag in development when compared with term infants that persists throughout most of the first postnatal year $(5,17)$. The amount of lag at about the 40th postnatal week is equivalent to the number of weeks before term that the infant is born (5). In addition, maturation of electroencephalographic patterns in perinates appears to be more a function of total age than of length of gestation or postnatal age alone $(4,6,9,16)$. These observations are in keeping with the idea that early development (i.e., central 


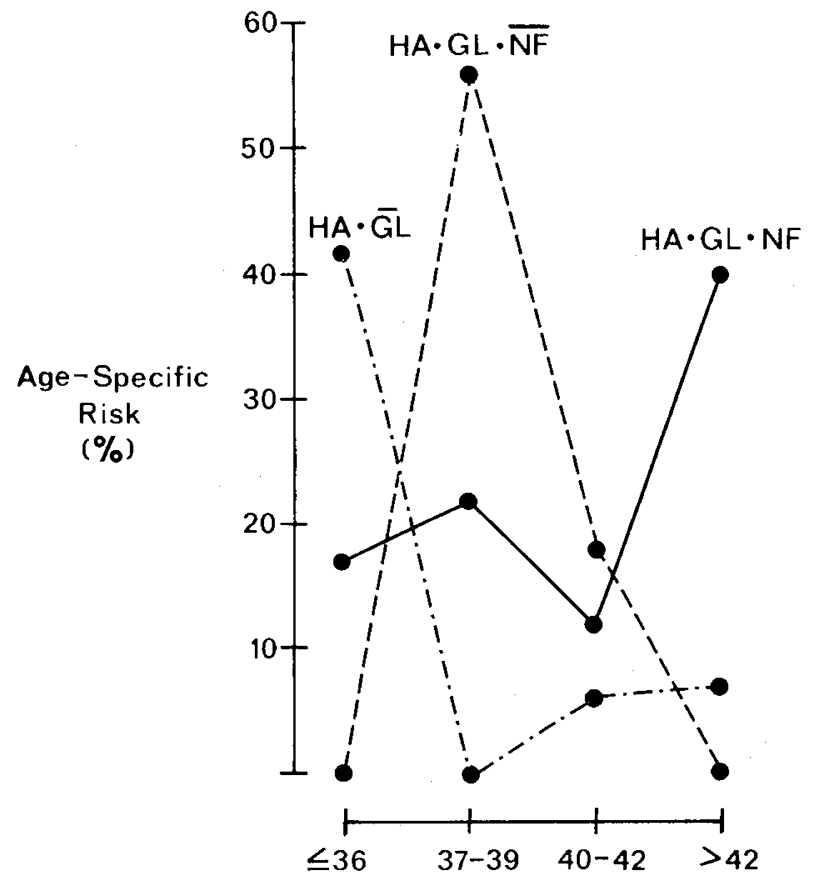

Total (Gestational plus Postnatal) Age

Fig. 1. In infants who had bacteria in cardiac blood aspirated at autopsy the peak risk of hypertrophic astrocytes without accompanying amphophilic globules $(H A \cdot \bar{G} L)$ occurred at a younger total age than the peak risk of hypertrophic astrocytes and amphophilic globules without accompanying necrotic foci $(H A \cdot G L \cdot \overline{N F})$ which in turn occurred at a younger age than the combination of hypertrophic astrocytes, amphophilic globules and necrotic foci $(H A \cdot G L \cdot N F)$. These findings are viewed as compatible with the hypothesis that, in infants with bacteremia, morphologic abnormalities in cerebral white matter are a function of gestational plus postnatal age.

nervous system maturation) is a function of total age. The responsiveness of cells within infant cerebral white matter to an insult may also be a function of total age. Support for this comes from the observations reported here that, in infants with $\mathrm{PMB}$, the pattern of white matter abnormalities appears to correlate with both gestational age (preterm or term) and postnatal age.

A total age was therefore calculated for each infant. Patterns of white matter abnormalities were then evaluated as a function of total age. The sequential progression with total age of peak risks of $\mathrm{HA} \cdot \overline{\mathrm{GL}}, \mathrm{HA} \cdot \mathrm{GL} \cdot \overline{\mathrm{NF}}$, and $\mathrm{HA} \cdot \mathrm{GL} \cdot \mathrm{NF}$ in infants with $\mathrm{PMB}$ is compatible with the hypothesis that the response of infant white matter to $\mathrm{PMB}$ is a function of gestational plus postnatal age.

Copyright $\odot 1974$ International Pediatric Research Foundation, Inc.

\section{REFERENCES AND NOTES}

1. Blanc, W. A.: Pathways of fetal and early neonatal infection. J. Pediat., 59: 473 (1961).

2. Cochran, W. G.: Some methods for strengthening the common $\chi^{2}$ tests. Biometrics, 10:417 (1954).

3. Davies, P. A.: Bacterial infection in the fetus and newborn. Arch. Dis. Childhood, 46: 1 (1971).

4. Dreyfus-Brisac, C.: The electroencephalogram of the premature and full-term infant. In: P. Kellaway and I. Petersen: Neurologic and Electroencephalographic Correlative Studies in Infancy (Grune \& Stratton, New York, 1964).

5. Eaves, L. C., Nuttal, J. C., Klonoff, H., and Dunn, H. G.: Developmental and psychological test scores in children of low birth weight. Pediatrics, 45: 9(1970).

6. Eisengart, M., Gluck, L., and Glaser, G. H.: Maturation of the electroencephalogram of infants of short gestation. Dev. Med. Child. Neurol., 12: 49 (1970).

7. Gilles, F. H., Leviton, A., and Kerr, C.S.: Susceptibility of neonatal feline telencephalic white matter to a lipopolysaccharide (Submitted for publication)

8. Gilles, F. H., and Murphy, S. F.: Perinatal telencephalic leucoen cephalopthy. J. Neurol. Neurosurg. Psychiat., 32: 404 (1969).

9. Goldie, L., Swedsen-Rhodes, U., Easton, J., and Robertson, N. R. C.: The development of innate sleep rhythms in short gestation infants. Dev. Med. Child. Neurol., 13: 40 (1971).

10. Gotoff, S. P., and Behrman, R. E.: Neonatal septicemia. J. Pediat., 76: $142(1970)$.

11. Gruenwald, P., and Minh, H. N.: Evaluation of body and organ weights in perinatal pathology. Amer. J. Clin. Pathol., 34: 247 (1960).

12. Kissane, J. M., and Smith, M. G.: Pathology of Infancy and Childhood (C. V. Mosby Company, St. Louis, (1967).

13. Leviton, A., and Gilles, F. H.: Clustering of the morphological components of perinatal telencephalic leucoencephalopathy. J. Neurol. Neurosurg. Psychiat., 34: 642 (1971).

14. Leviton, A., and Gilles, F. H.: Morphologic correlates of age at death in infants with perinatal telencephalic leucoencephalopathy. Amer. J. Pathol. 65: 303 (1971).

15. Leviton, A., and Gilles, F. H.: An epidemiologic study of perinatal telencephalic leucoencephalopathy in an autopsy population. $J$. Neurol. Sci., 18: 53 (1973).

16. Parmelee, A. H., Schulte, F. J., Akiyama, Y., Wenner, W. H., Schultz, M. A., and Stern, F.: Maturation of EEG activity during sleep in premature infants. Electroencephalogr. Clin. Neurophysiol., 24: 319 (1968).

17. Parmelee, A. H., and Schulte, F. J.: Developmental testing of pre-term and small for date infants. Pediatrics, 45: 21 (1970).

18. The absence of a characteristic is represented by a bar above it. Use of the dot means that the characteristics to the right and to the left are satisfied. $\mathrm{HA} \cdot \overline{\mathrm{GL}}$ therefore refers to those infants with HA but without GL.

19. The authors are indebted to Mrs. Denise Osterberg for manuscript preparation.

20. This research was supported in part by funds provided by the United Cerebral Palsy Research and Educational Foundation (R-224-69), by the Program-Project Grant no. NSI-EP, 1 P01 NS 09704-01 NSPA, HD, NINDS, and The Children's Hospital Medical Center Mental Retardation and Human Development Research Program (HD 03-0773). NICHD.

21. Requests for reprints should be addressed to: F. H. Gilles, M.D. Department of Pathology (Neuropathology), The Children's Hospital Medical Center, 300 Longwood Ave. Boston, Mass. 02115 (USA).

22. Accepted for publication March 12, 1974. 